\title{
Çimento Toz Emisyonlarının Bazı Bitkilerin Yapı ve Metabolitlerine Etkileri
}

\author{
Yalçın Kemal BAYHAN \\ Atatürk Üniversitesi, Mühendislik Fakültesi, Çevre Mühendisliği Bölümü, Erzurum \\ Sorumlu yazar: ybayhan@atauni.edu.tr
}

Geliş Tarihi: 08.12.2015

\begin{abstract}
Özet
Günümüzde endüstriyel gelişmeye paralel olarak büyük boyutlarda çevre kirliliği ortaya çıkmıştır. Ülkemizde bu gelişmeye bağlı olarak çeşitli sanayi kuruluşları işletmeye açılmış olup, bunların ekolojik denge üzerine etkileri hesaba katılmamıştır. Genelde işletmeler bazı nedenlerden dolayı tarım arazileri ya da doğal çayır ve meralar üzerine kurulmuştur. Bu çalışmada, hava kökenli kirletici parametrelerden olan toz partiküllerin bazı bitkiler üzerine etkisi incelenmiştir. Amaca yönelik olarak kültür bitkisi olarak yonca, doğal bitki ayrık otu ağaç türü olarak ise kavak incelenmeye alınmıştır. Çimento Fabrikası'nın yakın (yaklaşık 100 m.)ve uzak(yaklaşık 500 m.) çevresinden toplanan bitki örneklerinin toplam klorofil, karbonhidrat ve kuru madde miktarlarının nasıl ve hangi yönde değiştiği araştırılmıştır. Sonuç olarak, çevreye yayılan çimento toz emisyonlarının bitkilerin gelişiminde olumsuz etkiler yaptığı gözlenmiştir. İstatistiki olarak sırasıyla klorofil için önemli $\mathrm{P}<0.01$; karbonhidrat için özellikle çayır mera bitkisi olan ayrık otunda oldukça önemli $\mathrm{P}<0.005$, diğer türlerde önemli $\mathrm{P}<0.01$; kuru madde miktarı için ise yonca ve kavak yapraklarında önem seviyesi $\mathrm{P}<0.01$ olmakla beraber gövdelerinde oldukça önemli $\mathrm{P}<$ 0.005 olarak azalmalar belirlenmiştir. Toz emisyonlarının özellikle bitki yapraklarının üzerini örterek fotosenteze olumsuz etki yaptığı ve böylece bazı metabolik ürünlerin seviyelerinde azalmalara neden olduğu saptanmıştır.
\end{abstract}

Anahtar kelimeler: Çimento tozu, toplam klorofil, kuru madde, toplam karbonhidrat

\section{Abstract}

Effects of Some Plants Structure and the Metabolites of Cement Dust Emissions

Nowadays environmental pollution in great dimensions has occurred parallel to industrial development. In our country, various industrial foundations have been opened to work due to this development and the effect of these on ecology haven't been taken into consideration. Generally, the Plants were established on agricultural fields or natural grass and pastures because of some reasons. In this study, the effect of dust particles which are air originated pollutant parameters on some plants have been studied. According to the aim, cultural (Medicago sativa) and natural plant (Agropyron sp.) with a tree (Populus nigra) were examined. In which direction and how to change total amount of chlorophyll, carbohydrate and dry matter of the plant samples picked up nearby $(100 \mathrm{~m}$.) and far from $(500 \mathrm{~m}$.) the cement factory which spreads dust particles to the environment was studied. As a result, it has been observed that cement dust emissions spread to the environment have negative effects on the development of plants. Statistically, the reduction in chlorophyll $\mathrm{P}<0.01$ (significant); carbohydrates reduction in Agropyron sp., a grassland plants, $<0.005$ (very significant), in other species $\mathrm{P}<0.01$ (significant); the amount of dry matter in Medicago sativa and Populus nigra leaf $\mathrm{P}<0.01$ (significant); and in their body $<0.005$ (very significant), was identified, respectively. It has been determined that especially dust emissions have a negative effect on photosynthesis by covering the leaves of plants, so they cause a decrease at the levels of some metabolic products.

Key Word: Cement dust, total chlorophyll, dry matter, total carbohydrate

\section{Giriş}

Dünyanın bir çok ülkesinde olduğu gibi ülkemizde de özellikle 1970 'li y1llardan sonra "çevre sorunları", "çevre kirliliği" gibi terimler günlük hayatta s1k sık karşılaşılan ve konuşulan terimler olmuşlardır. Çevre sorunlarını çözmek veya çevre kirlenmesinin önüne geçmek için gerekli önlemler öncelikle kirletici kaynaklarda alınmalıdır. $\mathrm{Bu}$ yüzden alıcı ortam denilen çevreye yapılacak herhangi bir atık atımı ancak mecbur ve doğaya en az zararlı bileşimde 
olmalıdır. Araştırmaya konu olan katı partikül olarak çimento tozları da hava kalitesini olumsuz yönde etkilemektedir. Hava kirletici ve bitkilere zararlı etkisi olan partiküllerin kaynağı özellikle çimento fabrikaları olmakla beraber enerji santralleri, taş kırma ocakları tarımsal çalışmalar demir çelik imalathaneleri ve orman ürünleri işletmeleridir (Vandergrift ve ark. 1971)

Çimento üretimi sırasında oluşan çeșitli boyutlardaki tozlar ve diğer gaz kirleticiler önemli hava kirleticileridir. Hava kirliliği sorunu oluşturan çimento tozu zehirli, yanıcı ve patlayıcı olmadığı gibi insan sağlığına da zararlı değildir. Fakat kirleticilerin akciğerlerin "alveoller" bölgesinde birikmesi özellikle önemlidir. Çünkü bu bölgede partikülleri uzaklaştırmaya yarayan "titrek tüyler" adı verilen tüycükler mevcut değildir. Büyüklükleri 0.1 mikrondan daha küçük çaplı olan partiküller Brownian hareketi sayesinde akciğerlerin hava torbalarına kadar gitmekte ve buradaki "alveoli" denilen çukurlara yerleşmektedir. Genelde 1 mikrondan büyük partiküller bu bölgeye ulaşmadan tutulmaktadır (Karpuzcu, 1988). Çimento fabrikaları genelde büyük yerleșim merkezlerinden uzakta kurulduklarından özellikle kırsal bölgelere olumsuz etki etmektedir (Anonim, 1983). Ayrica bu tozlar atmosfer koşullarının da etkisiyle çok geniş alanlara yayılarak çevrede bulunan bitkiler üzerinde birikmekte ve bunların normal gelişimine engel olmakta (Mutlu ve ark. 2013, Cireli, 1975, Katırcığlu ve Iren, 1988; Brandt ve Rhoades, 1973) floristik kompozisyonu etkilemekte (Sheikh ve ark., 1976; Brandt ve Rhoades, 1972), bunun yanı sıra toprağın kimyasal yapısını değiştirmekte (Bayhan ve ark. 2002, Sheikhve ark., 1976, Brands ve Rhoades, 1973, Voran, 1984) topraktaki mikrobiyal türlere ve aktiviteye de olumsuz etki etmektedir (Bilen 2010, Hasenekoğlu ve Sülün 1991, Lux 1974). Bu olumsuz etkileri belirlemek amaciyla Almanya'da Pinus sylvestris (Lux, 1974), Amerika da Ouercus ağaçlarında klorozis, yaprak ve dal kurumas1 hatta tamamen kuruma olduğu (Rhoads, 1976) gözlenmiştir. Güneybatı Virjinya da seçilen dört tür orman bitkisinin lateral büyümesinin olumsuz etkilendiği (Brandt ve Rhoades, 1972, 1973), Lafraguta ve ark. (2014), ise çimento tozlu solüsyonun Medicago sativa (yonca) bitkisinin çimlenmesini olumsuz etkilediğini belirtmişlerdir. İzmir Bornova yakınlarında çimento tozlarının zeytin ağaçları üzerine etkileri (Sheikh ve ark.1976) tarafindan araştırılmış, büyüme ve gelişim üzerine zararlı etkileri olduğu tespit edilmiştir. Ayrıca kontrollü ortam çalışmalarında buğday fasulye ve elma bitkileri üzerine değişik periyot ve miktarlarda çimento tozu uygulanarak değişimler araştırılmıştır(Singh ve Rao, 1981; Katırcioğlu ve İren, 1988).

Bu çalışmada Erzurum - Aşkale Çimento Fabrikası'nın revize edilmeden önce ortama yaydığı toz partiküllerinin çevrede bulunan bitkilerin klorofil a, klorofil b, toplam klorofil, karbonhidrat ve kuru madde miktarlarında nasıl bir değişikliğe yol açtıkları araştırılmıştır.

\section{Materyal ve Metot}

\section{Materyal}

İnceleme alanı olarak, revize edilmeden önce Erzurum iline bağlı Aşkale ilçesinin kuzeydoğusundaki Aşkale Çimento Fabrikasının çevresi seçilmiştir. $\mathrm{Bu}$ çalışmada çimento Fabrikası'nın yakınından (yaklaşı $100 \mathrm{~m}$.) ve kirliliğin daha az görüldügüü noktalardan (yaklaşık 500m.) her bitki türü için beş ayrı örnek toplanmıştır. İnceleme amaciyla araziden ayrı otu (Agropyron sp.) yonca (Medicago sativa) bitki ve kavak ağacı (Populus nigra) örneklerinin toplama ve muhafaza işlemleri Kaçar (1972)' 'a göre yapılmıştır. Kullanılan kimyasallar analitik saflıktadır.

\section{Metot}

Toplanan bitki örnekleri çeşme suyu altında onar dakikalık süre ve aynı şekilde yıkamaya tabii tutularak işleme hazır hale getirilmiştir. Analizler her bir bitki türü için beş farklı örnekte gerçekleştirilmiştir.

$\mathrm{Bu}$ işlemler hem yaprak hem de gövde örnekleri için yapılmıştır. Bitki örnekleri kurulandıktan sonra tartılmış, daha sonra 80 ${ }^{\circ} C^{\prime}$ 'ye ayarlı etüvde sabit ağırlığa gelinceye bekletilmiş ve kuru madde miktarları belirlenmiştir (Singh ve Rao, 1981).

Taze yaprak dokularındaki klorofil miktarının belirlenmesi için klorofil a ve klorofil $\mathrm{b}$ analizleri yapılmıştır. $\mathrm{Bu}$ amaçla taze yaprak dokuları tartılıp, $20 \mathrm{ml} \% 80$ 'lik (Aseton : Su, 4:1, hacim/hacim) aseton 
içerisinde ezilmiştir. Alınan her örnek için aynı yöntem uygulanmıştır. Elde edilen karışım çift kat bir bezden süzülerek, $3000 \mathrm{x}$ $\mathrm{g}$ hızda 15 dakika santrifüj edilmiştir. Klorofil özütünün optikal yoğunluğu 645 ve 663 nanometre dalga boylarına ayarlanabilen kompüterize kolorimetre (Shimadzu, UV-160 A, UV- Spectrophotometer). ile belirlenmiştir. Klorofil a ve b miktarları, $\mathrm{mg} / \mathrm{g}$ taze yaprak olarak aşağıdaki formüller yardımıyla hesap edilmiştir (Sing ve Rao, 1981).

$$
\begin{aligned}
& 12.3 \times \mathrm{D}_{663}-0.86 \times \mathrm{D}_{645}
\end{aligned}
$$

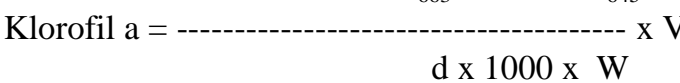

$19.3 \times \mathrm{D}_{645}-3.6 \times \mathrm{D}_{663}$

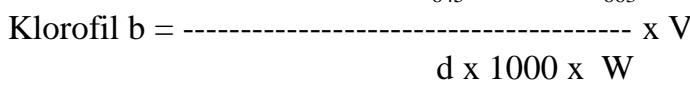

Denememizde klorofil a ve b'nin miktarlarının toplanmasıyla $1 \mathrm{~g}$ taze yaprak dokusundaki toplam klorofil miktarı belirlenmiştir.

Yaprak dokusundaki karbonhidrat miktarının belirlenmesi için Norris ve Ribbons (1971) fenolik-sülfür yöntemi kullanılmıştır. Bu amaçla dokudaki hekzoz ve pentozlar spektrofotometrik olarak belirlenmiştir.

Elde edilen bulgularla tozdan etkilenen ve etkilenmeyen bitki örnekleri kendi aralarında karşılaştırılmıştır. Sonuçların istatistiki olarak değerlendirilmesi Düzgüneş (1963)'e göre yapılmış ve yüzde azalma oranlarının anlamlı olup olmadığı belirlenmeye çalışılmıştır.

\section{Bulgular ve Tartıșma}

Bitkiler bulundukları ortam koşullarından büyük ölçüde etkilenmektedirler. Bunun sonucu olarak bitki organellerinde ve metabolik ürünlerinde değişiklikler saptanmaktadır. Bilindiği gibi bitkilerin büyüme ve gelişmesini sağlayan en önemli organellerden birisi olan kloroplastlar organik maddelerin sentezlenmesinde etkin rol almaktadır.

\begin{tabular}{|c|c|c|c|c|c|c|c|c|c|}
\hline \multirow{2}{*}{$\begin{array}{l}\text { BİTKI் } \\
\text { TÜRÜ }\end{array}$} & \multirow{2}{*}{ ÖRNEKLEME } & \multirow{2}{*}{$\begin{array}{c}\text { ÖLÇÜLEN } \\
\text { PARAMETRE }\end{array}$} & \multicolumn{5}{|c|}{ KLOROFİL MİKTARLARI (mg/g) } & \multirow{2}{*}{ ORT. } & \multirow{2}{*}{$\stackrel{\%}{\text { DEĞİŞì }}$} \\
\hline & & & I & II & III & IV & $\mathbf{V}$ & & \\
\hline \multirow{6}{*}{$\frac{y}{2}$} & \multirow{3}{*}{ TOZSUZ } & Klorofil a & 0.668 & 0.594 & 0.674 & 0.716 & 0.755 & 0.681 & \multirow{6}{*}{16,42} \\
\hline & & Klorofil b & 0.359 & 0.349 & 0.332 & 0.353 & 0.407 & 0.360 & \\
\hline & & Toplam Klorofil & 1.027 & 0.943 & 1.005 & 1.068 & 1.162 & 1.041 & \\
\hline & \multirow{3}{*}{ TOZLU } & Klorofil a & 0.577 & 0.473 & 0.549 & 0.496 & 0.586 & 0.536 & \\
\hline & & Klorofil b & 0.354 & 0.290 & 0.258 & 0.359 & 0.407 & 0.334 & \\
\hline & & Toplam Klorofil & 0.931 & 0.763 & 0.807 & 0.855 & 0.993 & 0.870 & \\
\hline \multirow{6}{*}{ 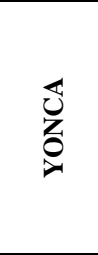 } & \multirow{3}{*}{ TOZSUZ } & Klorofil a & 0.806 & 0.728 & 0.740 & 0.900 & 0.883 & 0.911 & \multirow{6}{*}{26,98} \\
\hline & & Klorofil b & 0.434 & 0.409 & 0.473 & 0.404 & 0.564 & 0.547 & \\
\hline & & Toplam Klorofil & 1.240 & 1.137 & 1.214 & 1.305 & 1.447 & 1.308 & \\
\hline & \multirow{3}{*}{ TOZLU } & Klorofil a & 0.568 & 0.490 & 0.571 & 0.679 & 0.780 & 0.618 & \\
\hline & & Klorofil b & 0.306 & 0.300 & 0.281 & 0.320 & 0.478 & 0.337 & \\
\hline & & Toplam Klorofil & 0.874 & 0.790 & 0.852 & 0.999 & 1.258 & 0.955 & \\
\hline \multirow{6}{*}{$\frac{1}{2}$} & \multirow{3}{*}{ TOZSUZ } & Klorofil a & 0.718 & 0.618 & 0.735 & 0.720 & 0.876 & 0.733 & \multirow{6}{*}{26,21} \\
\hline & & Klorofil b & 0.386 & 0.395 & 0.346 & 0.441 & 0.412 & 0.396 & \\
\hline & & Toplam Klorofil & 1.104 & 1.012 & 1.080 & 1.162 & 1.288 & 1.129 & \\
\hline & \multirow{3}{*}{ TOZLU } & Klorofil a & 0.465 & 0.418 & 0.460 & 0.542 & 0.715 & 0.520 & \\
\hline & & Klorofil b & 0.285 & 0.256 & 0.270 & 0.332 & 0.420 & 0.313 & \\
\hline & & Toplam Klorofil & 0.750 & 0.674 & 0.730 & 0.875 & 1.136 & 0.833 & \\
\hline
\end{tabular}

Tablo 1. Klorofil miktarları 
Klorofil analiz sonuçları Tablo 1'de verilmiştir. Taze yaprak dokularında yapılan klorofil a ve klorofil b analizlerinde, tozdan etkilenen bölgede yetișen bitkilerin toplam klorofil miktarlarının tozdan etkilenmeyen bölgedeki bitki örneklerine göre, istatistiki olarak önemli sayılabilecek azalmalar gösterdiği saptanmıştır $(\mathrm{P}<0.01)$. Ayçiçeği (Borka, 1980), buğday (Singh ve Rao, 1981), misır ve kavak (Cireli, 1975) bitkileri üzerinde yapılan çalışmalarda da benzer bulgular elde edilmiştir. Ayrıca Katırcıoğlu ve İren (1988) yaptı̆̆ çalışmasıyla, toz emisyonlarından etkilenen fasulye ve elma bitkilerinde \% 29 oranında klorofil azalması saptamıştır. Czaja (1966) ve Lerman (1972), klorofil miktarındaki azalmaların doğrudan fotosentezi ve dolayısıyla bitki büyümesi ve gelişmesini olumsuz yönde etkilediğini göstermişlerdir. Biriken tozların alkali çözeltiye dönüşmesiyle epidermisten palizat ve sünger parankimasina kadar ilerlediklerini, kloroplastları tahrip ederek dokulara zarar verdiklerini çeşitli denemelerde kanıtlamışlardır (Katırcıoğlu ve İren, 1984). Klorofil miktarının azalmasına ve dolayısıyla fotosentez hızının düşmesine neden olan çimento tozlarının, dokularda kuru madde ve karbonhidrat miktarlarına da etki ederek bitki büyüme ve gelişmesinde olumsuzluklar yarattığı konusunda çeşitli çalışmalar yapılmıştır.

Tablo 2. Karbonhidrat miktarları

\begin{tabular}{|c|c|c|c|c|c|c|c|c|c|}
\hline \multirow{2}{*}{$\begin{array}{l}\text { BİTKİ } \\
\text { TÜRÜ }\end{array}$} & \multirow{2}{*}{ ÖRNEKLEME } & \multirow{2}{*}{$\begin{array}{c}\text { ÖLÇÜLEN } \\
\text { PARAMETRE }\end{array}$} & \multicolumn{5}{|c|}{ KARBONHIDDAT MIKTARLARI (mg/g) } & \multirow{2}{*}{ ORT. } & \multirow{2}{*}{$\begin{array}{c}\% \\
\text { DEĞíşìiM }\end{array}$} \\
\hline & & & $\mathbf{I}$ & II & III & IV & $\mathbf{v}$ & & \\
\hline \multirow{6}{*}{ 送 } & \multirow{3}{*}{ TOZSUZ } & Heksoz & 1.657 & 1.700 & 1.256 & 1.606 & 1.450 & 1.534 & \multirow{6}{*}{23,66} \\
\hline & & Pentoz & 1.052 & 1.147 & 0.918 & 1.108 & 1.017 & 1.048 & \\
\hline & & T. Karbonhidrat & 2.709 & 2.847 & 2.174 & 2.714 & 2.467 & 2.582 & \\
\hline & \multirow{3}{*}{ TOZLU } & Heksoz & 1.062 & 1.365 & 1.059 & 1.113 & 1.093 & 1.138 & \\
\hline & & Pentoz & 0.786 & 1.135 & 0.719 & 0.754 & 0.766 & 0.832 & \\
\hline & & T. Karbonhidrat & 1.848 & 2.500 & 1.778 & 1.867 & 1.860 & 1.971 & \\
\hline \multirow{6}{*}{$\begin{array}{l}\widetilde{Z} \\
\vdots \\
0\end{array}$} & \multirow{3}{*}{ TOZSUZ } & Heksoz & 1.955 & 1.733 & 1.714 & 2.006 & 1.817 & 1.845 & \multirow{6}{*}{14,77} \\
\hline & & Pentoz & 1.686 & 1.527 & 1.393 & 1.675 & 1.585 & 1.573 & \\
\hline & & T. Karbonhidrat & 3.641 & 3.260 & 3.107 & 3.681 & 3.402 & 3.418 & \\
\hline & \multirow{3}{*}{ TOZLU } & Heksoz & 1.817 & 1.502 & 1.514 & 1.763 & 1.459 & 1.611 & \\
\hline & & Pentoz & 1.395 & 1.242 & 1.126 & 1.505 & 1.241 & 1.302 & \\
\hline & & T. Karbonhidrat & 3.212 & 2.744 & 2.640 & 3.268 & 2.700 & 2.913 & \\
\hline \multirow{6}{*}{$\underset{4}{\mathbb{4}}$} & \multirow{3}{*}{ TOZSUZ } & Heksoz & 0.544 & 0.638 & 0.961 & 0.607 & 0.740 & 0.698 & \multirow{6}{*}{23,43} \\
\hline & & Pentoz & 0.480 & 0.616 & 0.590 & 0.559 & 0.497 & 0.548 & \\
\hline & & T. Karbonhidrat & 1.024 & 1.254 & 1.551 & 1.166 & 1.237 & 1.246 & \\
\hline & \multirow{3}{*}{ TOZLU } & Heksoz & 0.475 & 0.479 & 0.492 & 0.576 & 0.470 & 0.498 & \\
\hline & & Pentoz & 0.429 & 0.440 & 0.447 & 0.508 & 0.449 & 0.456 & \\
\hline & & T. Karbonhidrat & 0.904 & 0.919 & 0.939 & 1.084 & 0.919 & 0.954 & \\
\hline
\end{tabular}

Tablo 2 görüldüğü gibi toz emisyonlarının etkili olduğu noktalardaki örneklerde karbonhidrat miktarlarındaki istatistiki olarak özellikle çayır mera bitkisi olan ayrık otunda oldukça önemli( $\mathrm{P}<0.005)$ diğer türlerde önemli $(\mathrm{P}<0.01)$ azalmalar belirlenmiştir. Bazı araştırıcılar da yaptıkları çalışmalarla benzer bulgular elde etmişlerdir. Lerman (1972) bezelye, Anda (1986) misir, Katırcıŏlu ve İrem (1988) fasulye ve elma ile ilgili yaptıkları araştırmalarda, toz miktarındaki artışa bağlı olarak nişasta ve şeker düzeylerinde azalmalar olduğunu bildirmişlerdir.

Tablo 3 incelendiğinde, kirli bölgelerde yetişen bitkilerde, temiz bölge bitkilerine oranla istatistiki yönden önemli sayılabilecek azalmalar olduğu görülecektir. Yonca ve kavak yapraklarındaki kuru madde miktarı için önem seviyesi $\mathrm{P}<0.01$ olmakla beraber gövdelerinde de bu seviye $\mathrm{P}<0.005$ 'dir. Ayrik otunda ise yaprak ve gövdedeki kuru madde miktarındaki azalma oldukça önemli seviyededir $(\mathrm{P}<0.005)$. 
Tablo 3. Kuru madde miktarları

\begin{tabular}{|c|c|c|c|c|c|c|c|c|c|}
\hline \multirow{2}{*}{$\begin{array}{l}\text { BİTKİ } \\
\text { TÜRÜ }\end{array}$} & \multirow{2}{*}{\multicolumn{2}{|c|}{ ÖRNEKLEME }} & \multicolumn{5}{|c|}{ KURU MADDE MIKKTARI (g/g) } & \multirow{3}{*}{$\begin{array}{c}\text { ORT. } \\
0,57\end{array}$} & \multirow{2}{*}{ \% DEĞisșiM } \\
\hline & & & I & II & III & IV & $\mathbf{V}$ & & \\
\hline \multirow{4}{*}{ AYRIK } & \multirow{2}{*}{ YAPRAK } & Tozlu & 0,54 & 0,60 & 0,58 & 0,58 & 0,56 & & \multirow{2}{*}{15,79} \\
\hline & & Tozsuz & 0,46 & 0,49 & 0,52 & 0,46 & 0,46 & 0,48 & \\
\hline & \multirow{2}{*}{ GÖVDE } & Tozlu & 0,68 & 0,68 & 0,59 & 0,71 & 0,69 & 0,67 & \multirow{2}{*}{13,43} \\
\hline & & Tozsuz & 0,59 & 0,58 & 0,50 & 0,65 & 0,60 & 0,58 & \\
\hline \multirow{4}{*}{ YONCA } & \multirow[b]{2}{*}{ YAPRAK } & Tozlu & 0,42 & 0,48 & 0,36 & 0,39 & 0,44 & 0,42 & \multirow[b]{2}{*}{23,81} \\
\hline & & Tozsuz & 0,38 & 0,33 & 0,33 & 0,23 & 0,35 & 0,32 & \\
\hline & \multirow[b]{2}{*}{ GÖVDE } & Tozlu & 0,52 & 0,50 & 0,55 & 0,52 & 0,54 & 0,53 & \multirow[b]{2}{*}{13,20} \\
\hline & & Tozsuz & 0,44 & 0,44 & 0,47 & 0,48 & 0,49 & 0,46 & \\
\hline \multirow{4}{*}{ KAVAK } & \multirow[b]{2}{*}{ YAPRAK } & Tozlu & 0,37 & 0,46 & 0,48 & 0,36 & 0,41 & 0,41 & \multirow[b]{2}{*}{21,95} \\
\hline & & Tozsuz & 0,30 & 0,38 & 0,29 & 0,34 & 0,30 & 0,32 & \\
\hline & \multirow{2}{*}{ GÖVDE } & Tozlu & 0,56 & 0,61 & 0,64 & 0,56 & 0,60 & 0,59 & \multirow[b]{2}{*}{20,33} \\
\hline & & Tozsuz & 0,45 & 0,44 & 0,45 & 0,50 & 0,49 & 0,47 & \\
\hline
\end{tabular}

Kirleticilerin bitkilerdeki kuru madde miktarı üzerine etkileri ile ilgili yapılan diğer çalışmalarda da benzer sonuçlar bulunmuştur. Çeşitli araştırmalarla, zeytin ağaçlarında kuru madde miktarının önemli ölçüde azaldığ (Sheik ve ark. 1976), mısır bitkisinde kuru madde miktarında düşüşler meydana geldiği (Anda, 1986) belirlenmiştir. Cireli (1975) ise kirleticilerin etkisi altında bulunan çeşitli bitkilerde kuru madde üretiminin düştüğü ve bu etkinin tozun bitkilerde fotosentez için elverişli 1şığın engellenmesine bağlı olarak meydana geldiğini rapor etmiştir.

Elde ettiğimiz bulgulara göre, çimento tozlarından etkilenen bitkilerde, klorofil ve metabolizma ürünlerinde azalmaların oluştuğu görülmüştür. Araştırmamız sonucu, bitkiler üzerinde biriken tozun, yapraklar üzerinde örtü tabakası oluşturarak, bitkiler için çok önemli olan 1 şı enerjisini engellemesi yanı sıra nem ile tepkimeye girip alkali çözelti meydana getirdiği saptanmıştır. Böylece toz emisyonları yapraklardaki kloroplastları tahrip ederek klorofil miktarını azalttığı ve dolaylı yönden fotosentez metabolizmasını yavaşlattığı tespit edilmiştir.

Bulgularımız sonucu, Çimento Fabrikası toz emisyonlarının çevresindeki çayır ve meralara ve diğer bitki örtüsü üzerine olumsuz etki yaptığı belirlenmiştir. Bu nedenle doğayı korumak için, eski teknolojilerle işletilmekte olan üretim tesislerinin yeni teknolojiler kullanılarak modernize edilmesini ve böylece çevreye daha az zarar verecek düzenlemelerin yapılmasını önerisine bağlı olarak ilgili fabrikada teknolojik yenilikler kullanılarak tozumanın önüne geçilmesi sağlanmıştır.

\section{Kaynaklar}

Anda, A., 1986, Effect of Cement -kiln Dust on the Radiation Balance and Yelds of Plant, Environmental Pollution, 40, 249-256.

Anonim, 1983, Türkiye'nin Çevre Sorunları, Türkiye Çevre Sorunları Vakfı Yayını, Önder Matbaas1, Ankara.

Bayhan, YK., Yapici, S., Kocaman, B., Nuhoglu, A., Cakici, A., 2002, The Effects of Cement Dust on Some Soil Characteristics, Fresenuus Environmental Bulletin, 11(11), 10301033

Borka , G., 1980, The Effect of Cement Dust Pollution on Growth and Metabolism of Helianthus Annus Environmental Pollution , 40, 249-256.

Bilen, S., 2010, Effect of Cement Dust Pollution on Microbial Properties and Enzyme Activities in Cultivated and No-till Soils, Arican Journal of Microbiolgy Research, 4(2), 24182425 .

Brandt, C.J. and Rhoades, R.W., 1972, Effects of Limestones Dust Accumulation on Composition of a Forest Community , Environmental Pollution, 3, 217-225.

Brandt, C.J. and Rhoades, R.W., 1973, Effects of Limestone Dust Accumulation on Lateral Growth of Forest Trees, Environmental Pollution, 4, 207-213.

Cireli, B., 1975, Endüstriyel Baca Gazlarının Nif Dağı Vejetasyonuna Etkileri, Bitki, 2, 2(2), 23-26.

Czaja, W., 1966, The Effect of Dust upon Plants, Angew. Bot. 40, 106-120.

Düzgüneş, O., 1963, Bilimsel Araştırmalarda İstatistik Prensipleri ve Metodları, Ankara Ünv. Ziraat Fak. Yayını.

Hasenekoğlu, İ., Sülün,Y., (1991). Erzurum Aşkale Çimento Fabrikasının Kirlettiği 
Toprakların Mikrofunfus Florası Üzerine bir Araştırma, Turk J Bot, 15, 20-27.

Kaçar, B., 1972, Bitki ve Toprağın Kimyasal Analizleri, Ankara Ün. Ziraat Fak. Yayını No. 453.

Karpuzcu, M., I988, Çevre Mühendisliğine Giriş. İ.T.Ü. inşaat Fakültesi Matbaası İstanbul, s 146.

Katırcıŏglu, Y.Z. ve İren, S., 1984. Çimento Firın Tozlarının Elma ve Fasulye Yapraklarının Anatomisine ve Elma Sürgünlerinin Morfolojisine Etkileri, TUBITAK Ulusal Çevre Sempozyomu, Adana.

Katırcioğlu, Y.Z. ve İren, S., 1988. Çimento Firın Tozlarının Elma ve Fasulye Bitkilerinin Fotosentezine Olan Olumsuz Etkileri, Çevre, 6, 31-44.

Lafraguta, C., Garcia-Criado, B., Arranz, A., Vazquez-de-Aldana, BR., 2014 Germination of Medicago sativa is Inhibited by Soluble Compounds in Cement Dust, Environmental Science and Pollution Research, 22(2), 128512901

Lerman, S., 1972, Cement-kiln Dust and the Bean Plant in-depth Investigations into Plant Morphology, Physcology and Patology, Ph. D. Dissertation, University of California, Riverside.

Lux, H., 1974, Contamination of the Top Soil in pinus sylvestris Stands by Basic Duste of Industrial Origin, Wissenschoffliche Zeatschrift der Technischen Univrsital Dresden 23, 915-920, 1974.

Mutlu, S., Atici, O., Gulen, Y., 2013, Cement Dust Pollution Induces Toxicity or Deficiency of some Essential Elements in Wild Plants Growing around a Cement Factory, Toxicology and industrial Health, 29(5), 474-480.

Norris,J.R, Ribbons, D.W., 1971, Methods in Microbiology, Vol. 5 B, 468-474, London.

Rhoads, A. F.,1976, forest species show a delayed response to cement dust in the soil. I Arbori. 2, 197-199

Singh S.N., Roa D.N., 1981 Certain responses of wheat plants to cement dust pollution. Environmental Pollution Series A, Ecological and Biological, Volume 24, Issue 1, Pages 75-81

Sheikh, H.K., Öztürk, M. ve Vardar, Y., 1976. Field Studies of the Effects of Cement Dust on the Growth and Yield of Olive Trees in Turkey, Environmental Conservation, 3(2), 117-121.

Vandegrift, A.E., Shannon, L.J., Sallee, E.E., Gorman, P.G. and Pork, W.R., 1971, Particulate Air Pollution in the United States, J.Air Pollut. Contr. Ass., 21, 321-8.

Voran, V.P., 1984, Pollution of Grey Forest Soils with Alkali and Alkaline-earth Metals in an
Area Affected by Cement Dust Emissions, Lesovodstvo Agrolesomelioratsiya 68, 27-31. 